\title{
Chapter 3 \\ Geospatial Applications in the HKH \\ Region: Country Needs and Priorities
}

\author{
Mir A. Matin and Sheikh Tawhidul Islam
}

\subsection{Introduction}

Geospatial information, defined as information that refers to a location on Earth, is becoming a critical tool in governance (Chantillon et al. 2017). Over the last decade, such information has become part of mainstream information management, thereby creating a massive demand for geospatial content and solutions among individuals, private companies, and government agencies. The industry has been growing at an annual rate of $14 \%$ and impacting the global economy at a rate of 18\% (GEOBUIZ 2018). Though the use of geoinformation in the $\mathrm{HKH}$ region started in the 1990s and while the application areas have been on the rise, the integration of geoinformation into the working of many key governmental agencies has not yet been achieved. The agencies in the region have had limited exposure to the latest developments in geospatial technologies. As the success of any information system depends on its usefulness for the intended target, in the context of the limited resources within the HKH region, it was crucial to understand the needs and priorities of the user agencies before planning to develop such a system.

This present study was commissioned by the SERVIR-HKH program to assess the situation in four countries-Afghanistan, Bangladesh, Nepal, and Pakistanregarding the decision-making processes at the institutional level (a total of 98 institutions were surveyed) and the capability of the institutions to use geospatial information in an effective manner. The study tried to identify the type of services these agencies provide and the kind of challenges they face regarding data and resources-hardware, software, human; it also attempted to understand the needs that have to be accounted for while producing decision-support products. The study

M. A. Matin $(\bowtie)$

International Centre for Integrated Mountain Development, Kathmandu, Nepal

e-mail: mir.matin@icimod.org

S. T. Islam

Institute of Remote Sensing, Jahangirnagar University, Dhaka, Bangladesh

(C) The Author(s) 2021

B. Bajracharya et al. (eds.), Earth Observation Science and Applications for Risk

Reduction and Enhanced Resilience in Hindu Kush Himalaya Region,

https://doi.org/10.1007/978-3-030-73569-2_3 
aimed to attain threefold objectives. First, to know the institutional structure and policies that provide geospatial- and climate-information services related to agriculture and food security, water resources and hydro-climatic disasters, land cover and land-use changes, as well as on weather and climate. Second, to determine the pattern of use of geospatial tools by the national agencies in decision-support systems and data-sharing mechanisms. Third, to identify potential areas of partnerships with agencies where geospatial applications could be used for providing services to communities/users/beneficiaries so that they are able to address the challenges they face, thereby reducing vulnerabilities and enhancing resilience against disaster.

\subsection{The Decision-Making Landscape}

A decision-making landscape includes different elements that create an enabling environment for the relevant agencies to deliver services that cater to the welfare of the intended recipient. The decision-making landscape in the government involves knowledge and action, societies, organizations, and individuals (Raadschelders and Whetsell 2017). In this landscape, geospatial technology has the capability of providing valuable tools that can seamlessly organize and analyze knowledge to support evidence-based and spatially-contextualized decisions. In the case of the HKH region, the decision-making processes are generally top-down where national policies define the activity mandates of the specific agencies and then resources are arranged to perform the duties. In order to respond to emergencies, the government usually has standard operating procedures (SOP) which define decision-making processes and the role of individual agencies. As for non-emergency issues such as the monitoring of natural resources, the mandated agencies develop their own priorities and procedures. Thus, in a bid to understand the overall decision-making landscape in the context of geospatial applications, we considered the following elements (Table 3.1).

Different public agencies, sometimes with support from national and international partner organizations, use geospatial tools and techniques to generate data for decision-making purposes. The primary application areas are for: monitoring a situation (e.g., occurrence of a disaster); natural resource appraisal/management and better land-use planning (by way of soil-suitability assessment, urban planning, and land-zoning exercises); forest and biodiversity assessment; and for providing climate services. In this regard, the agencies in the HKH region have been classified into four categories (Fig. 3.1). 
Table 3.1 Elements to understand decision-making landscape

\begin{tabular}{|c|c|}
\hline Objectives & Elements \\
\hline $\begin{array}{l}\text { To know about institutional structures } \\
\text { and policies }\end{array}$ & $\begin{array}{l}\text { - Assess the organogram of the organization } \\
\text { concerned to understand the decision-making } \\
\text { hierarchy and process } \\
\text { - Understand the contexts and contents of } \\
\text { decision-making (why decisions are made for } \\
\text { short and long terms; and what decision are } \\
\text { made) } \\
\text { - Understand the decision-making processes } \\
\text { during crises and challenging situations }\end{array}$ \\
\hline $\begin{array}{l}\text { To examine the current pattern of use of } \\
\text { geospatial data, tools, and methods }\end{array}$ & $\begin{array}{l}\text { - Analyze the inputs (e.g., data) that organizations } \\
\text { use to execute decisions } \\
\text { - Examine the level (e.g., local, regional, national) } \\
\text { of service delivery for different thematic areas } \\
\text { and use data appropriate for that scale } \\
\text { - Assess the provisions for data updates }\end{array}$ \\
\hline $\begin{array}{l}\text { To identify potential areas of } \\
\text { partnerships among the relevant } \\
\text { agencies }\end{array}$ & $\begin{array}{l}\text { - Study the current partnership process among } \\
\text { organizations } \\
\text { - Assess the service delivery processes (mapping } \\
\text { application, and data dissemination through } \\
\text { tables, documents, catalogues, and web portals) } \\
\text { - Examine mandates such as the National Spatial } \\
\text { Data Infrastructure (NSDI) that aims to facilitate } \\
\text { data-sharing provisions among partner agencies }\end{array}$ \\
\hline
\end{tabular}

\section{Primary data-generation agencies}

These agencies maintain an observation network to regularly collect data (such as on weather variables, and on surface and groundwater); they also carry out surveys (topographic and cadastral) and mapping (of land cover and infrastructure).

\section{Sector agencies}

These agencies are responsible for managing key areas such as agriculture and food security, environment/ ecosystem, health, infrastructure development and management, and national-, regional-, and local-level planning

\section{Agencies responsible for executing regulatory actions}

These agencies are responsible for regulatory actions to protect natural resources (like water, forests, and land) and to mitigate damages arising from changing climatic conditions.

\section{Agencies responsible for disaster management and monitoring climate change}

These agencies monitor and assess the impacts of climate change or climate variability; they are also engaged in disaster management.

Fig. 3.1 Types of agencies that provide services using geospatial data 


\subsection{Materials and Methods}

The research method had three components to understand the decision-making landscape. The first was a review of literature, mainly organizational reports, government policies, and published literature. The second was a survey of crucial agencies in Afghanistan, Bangladesh, and Nepal using a structured questionnaire to understand the practical realities of the agencies. A total of 98 agencies (15 from Afghanistan, 45 from Bangladesh, and 38 from Nepal) were surveyed for this institutional review (Table 3.2). However, due to logistic difficulties, the questionnaire survey could not be conducted in Pakistan. Thirdly, Key Informant Interviews (KIIs) were conducted with professionals to understand the challenges and to identify the areas of priority for better integration of geospatial applications into the decision-making processes. The combination of these three approaches helped in forming an understanding of the research elements. The literature review gave a broad idea about the historical progress of the decision-making landscape, about governmental policies, and the mandate of different agencies, and the relationship between these agencies. It provided an understanding of policies, procedures, macro-level challenges, and the condition of ICT infrastructure related to geospatial applications. The survey collected information about the capacity of the organizations (in terms of human resources, and hardware, and software) and the current use of geospatial information, and future priorities. The structured interviews became useful tools to collect information on predefined items from the different respondents (Marvasti 2004); these KIIs were aimed at collecting specific information from various organizations regarding their role, data capability, and capacity in terms of human and computing resources. In the first place, the organizations were identified through the literature review. Then the information that was gathered was organized into a database for analysis. A web-based data entry interface was also developed to enter/upload the collected data from the respective countries for compilation, tabulation, and analysis. Table 3.2 lists the number of organizations that were surveyed, country-wise and by themes.

In the particular case of Pakistan, despite it was not being part of the questionnaire survey, the country had always been a significant focus of the

Table 3.2 Number of agencies surveyed by theme and country

\begin{tabular}{l|l|l|l}
\hline \multirow{2}{*}{ Thematic areas } & \multicolumn{3}{l}{$\begin{array}{l}\text { Institutions surveyed in HKH countries } \\
\text { (total 98) }\end{array}$} \\
\cline { 2 - 4 } & Afghanistan & Bangladesh & Nepal \\
\hline Agriculture and food security & 3 & 11 & 10 \\
\hline Water resources and hydro-climatic disasters & 3 & 12 & 10 \\
\hline Land cover, land use, and ecosystems & 5 & 11 & 10 \\
\hline Weather and climate & 4 & 11 & 08 \\
\hline Total & $15(15.3 \%)$ & $45(46.9 \%)$ & $38(38.8 \%)$ \\
\hline
\end{tabular}


SERVIR-HKH project. So, in Islamabad, on 23 February 2016, the necessary data were collected through a stakeholder consultation process, jointly organized by ICIMOD and the Pakistan Council of Research in Water Resources (PCRWR). A total of 37 participants attended from 23 agencies and institutions from governmental and non-governmental sectors. The participants were divided into three groups and provided valuable inputs on: the availability of spatial data; the current service delivery processes where geospatial data, methods, techniques are used; and on the skills gaps in the geospatial applications. The participants identified the activities and ranked them on a priority basis. Process documentation was duly done, and a report was generated on the consultation processes. This report was used as a source of data for this research in Pakistan since direct data collection from the institutions was not possible due to logistical reasons.

\title{
3.4 Results and Discussions
}

\subsubsection{The Organizational Framework for Geospatial Applications in the HKH Countries}

\begin{abstract}
Afghanistan
During the last few decades, several projects have been implemented in Afghanistan to develop geospatial data and spatial data infrastructure. The Afghanistan Information Management Services (AIMS) was established in 1997 to process and disseminate geoinformation and build the capacity of the national agencies in this regard. Till 2009, several geospatial data sets and applications were developed through AIMS. More attempts were undertaken by the United States Geological Survey (USGS), UNDP, and other international organizations to establish a national spatial data infrastructure in the country. However, despite a massive number of projects and initiatives to implement geospatial information, the agencies in Afghanistan showed a limited capacity to develop and maintain geospatial applications. Among the institutions surveyed in Afghanistan was the National Environmental Protection Agency (NEPA), which is primarily responsible for monitoring and managing environmental resources and mainstreaming climate change activities. Then there is the Afghan Meteorological Department (AMD), the principal agency that monitors hydrometeorological variables with an advanced meteorological monitoring network. The Ministry of Agriculture, Irrigation and Livestock (MAIL), is responsible for natural resources exploitation, management, and conservation in the country; it also has a Statistics directorate with GIS facilities with dedicated human resources. Besides, MAIL has a network of stations to collect agrometeorological data for agriculture management. As for the Ministry of Energy and Water (MEW), it is responsible for all hydrological monitoring and water-related disaster monitoring. The Afghanistan National Disaster Management
\end{abstract}


Authority (ANDMA) has the mandate to deal with the impact of climate change in the country. It is the principal agency that coordinates the development of disaster-warning and disaster-risk reduction systems. On November 6, 2017, the President of Afghanistan endorsed the establishment of the National Geoinformation Center (NGIC) under the National Statistical and Information Authority (NSIA). NGIC (https://nsia.gov.af/) has been given the responsibility to coordinate all geospatial mapping and data management initiatives being carried out by all the relevant agencies aiming to provide coordinated access to all geospatial data. But all said, the Afghanistan experience tells us that the existence of a modest institutional and policy framework to deal with hydrometeorological and environmental challenges is not enough to deliver effective geospatial services. The problems are:

- Decision-making processes are generally top-down; identifying and understanding user needs are usually less prioritized in this region

- National-level decision-making processes generally guide agency-level decision-making activities

- Data-generation and data-sharing provisions are inadequate

- Agencies need skilled human resources and technical support for product/ service generation

- There is a need for continued international support to strengthen the capabilities of institutions such as universities in conducting research and providing training as well as in policy analysis in the various disciplines of environmental management

- Agro-meteorological data are available with MAIL, MEW, and AMD; they also collect hydro-meteorological data within their station networks; but the regular maintenance of stations and data management were challenging.

\section{Bangladesh}

In Bangladesh, the Space Research and Remote Sensing Organization (SPARRSO) and the Survey of Bangladesh (SoB) are the two mandated government agencies that promote remote-sensing and topographic information systems. A more extensive application of GIS and remote sensing started in the country in 1990 when the Bangladesh Flood Action Plan (FAP 19) set up a GIS facility under the Irrigation Support Project for Asia and the Near East (ISPAN) with funds from USAID. The project later transformed into the Centre for Environmental and Geographic Information Services (CEGIS) as a public trust in 2002. A similar project under the flood action plan responsible for hydrological modeling of flood and cyclone early warning systems transformed into the Institute of Water Modeling (IWM) in 1996. After that, the Local Government Engineering Department (LGED) established a GIS lab for mapping different levels of administrative units (such as thana maps). During the last three decades, many other governmental organizations have been adopting geospatial technology for analysis and spatial data management. In the agriculture and food security area, many of the agencies under the National Agricultural Research System (NARS) went on to establish a geospatial lab. Among them, the Bangladesh Agricultural Research 
Centre (BARC), the Soil Resources Development Institute (SRDI), Bangladesh Agriculture Research Institute (BARI), Bangladesh Rice Research Institute (BRRI), and the Department of Agriculture Extension (DAE) have excellent geospatial facilities. In this context, the development of Agro-Ecological Zones (AEZs) by BARC and soil maps by SRDI are the two significant data sets that have been developed, although updating of these data has not happened since its development. In the area of water resources and disaster, in 1998, CEGIS was able to develop a national water resources database for the Water Resources Planning Organization (WARPO); this is a comprehensive database containing most of the spatial data layers of Bangladesh. And since 1997, CEGIS has been using satellite data to monitor flood and erosion. Another critical spatial data are the detailed digital administrative boundary and infrastructure maps developed by LGED, which is used for many spatial applications. In the case of monitoring land-cover changes, it is the Bangladesh Forest Department (BFD) that is in charge. BFD has been producing land-cover maps since the 1990s and recently produced a series of land-cover maps (from 2000 to 2015) through funding from USAID and technical assistance from the Food and Agricultural Organization (FAO).

But while a number of projects have been implemented, funds expended, and data have been generated, the mainstreaming of geospatial technology for various services are still limited in the country. While CEGIS and IWM are maintaining good geospatial capability, the relevant government agencies are suffering from the lack of resources. Lack of coordination among the agencies, use of old data due to the absence of updating facilities, shortage of skilled human resources, ineffective data-sharing provisions, all are significant barriers in better use of geospatial technology in Bangladesh. The major challenges identified by the institutional review carried out in the country are:

- The current geospatial services are useful for short-term decision-making, but not for long-term forecasts by the decision makers

- Data consistency, quality, and outdated data are still concerns for different sectors

- The inadequate number of skilled human resources is a major problem

- Data-sharing provisions are weak among the Bangladeshi agencies and need to be improved because the services developed and provided by many agencies, such as BARC and DAE, depend on the geospatial data produced by other agencies. Any challenges in data sharing jeopardize the whole process

- Early warning facilities are in place for flood, riverbank erosion and cyclone hazards. But the early warning systems for drought, landslides, and thunderstorms are still non-existent.

- Applications of geospatial methods, tools, and data in monitoring and yield forecasting for different crops are very much required.

\section{Nepal}

Several agencies in Nepal use geospatial applications for different purposes. The Department of Land Information and Archive of the Government of Nepal is one of 
the principal agencies that manage land-ownership data for Nepal. The first detailed assessment and mapping of Nepal's land resources were carried out by the Land Resources Mapping Project (LRMP) under the auspices of this agency. The assessment and mapping were based on aerial photography conducted in 1978-79 and were supplemented by extensive field checks and sampling. And, between 1987 and 1998, the Department of Forest Research and Survey, later renamed as Forest Research and Training Centre (FRTC), conducted a nation-wide survey to prepare a National Forest Inventory (NFI). The Survey Department of Nepal has been gathering, managing, and archiving spatial data related to geodesy and preparation of topographic maps. Soil maps of Nepal have been developed for agricultural planning by the Soil Science Division of the Nepal Agricultural Research Council. The Department of Hydrology and Meteorology (DHM), under the Ministry of Energy, Water Resources and Irrigation, has been playing a significant role in generating in situ hydro-met data from a large number of stations; these data are primarily managed using the spatial data structure. Besides, the Central Bureau of Statistics, the Department of Irrigation, and the National Planning Commission of Nepal has been extensively using various kinds of social, economic, and demographic data for national-level planning activities and reporting purposes. On September 20, 2015, Nepal changed its constitution to transform the country into a federal system consisting of seven provinces and 753 local governments (including six metropolitan cities, 11 sub-metropolitan cities, 276 municipalities, and 460 rural municipalities). Many of the tasks, including disaster management, are now being carried out by the provincial governments. However, the spatial data have not yet been updated to reflect the new administrative structure. The responsibility of collecting hydro-meteorological data still lies with the DHM, which is centrally managed. Many international agencies, such as the World Food Programme of the United Nations and the WWF (World Wide Fund for Nature), undertake actions in the country wherein they widely use geospatial data, tools, and applications. The primary data gaps and challenges faced by Nepal are the following:

- There is a necessity to develop accurate baseline data/map on crop types and farming practices at the sub-district (Village Development Committee) level

- The existing spatial data need to be updated to reflect the new administrative changes and the relevant statistical data need to be synchronized with these changes

- There's a need to develop a comprehensive agricultural information system by putting together data in the form of crop statistics, market prices, irrigation systems, soil profiles, disease cycles, etc.

- District-level statistics on disasters (Devkota et al. 2012) are largely not available; this needs to be addressed

- The provision of suitable indices for meteorological drought, agricultural drought, and hydrological drought needs to be developed

- The existing flood risk management practices and the early warning system have to be improved and the lead time increased by using Earth observation applications. 


\section{Pakistan}

In Pakistan, the geospatial data are mainly produced and disseminated by government agencies as part of their mandated responsibilities (Ali and Ahmad 2013). The primary organizations producing geospatial data and conducting research for the government are the Survey of Pakistan (SoP), the Pakistan Space and Upper Atmosphere Research Commission (SUPARCO), the Pakistan Agricultural Research Council (PARC), and the Census Department. Here, it is also important to mention that individual researchers have produced a wealth of information on different themes. The significant area of research by these researchers has been on disaster management — primarily on droughts, floods (Gaurav et al. 2011; Haq et al. 2012), cyclones, earthquakes, and landslides. The researchers have also focused on crop-yield forecasting (Bastiaanssen and Ali 2003) and groundwater use and monitoring in large irrigated areas, especially in Rachna Doab. At the consultation workshop, the experts picked out eight significant areas where geospatial data and techniques are widely used (ICIMOD 2016). These are (i) crop monitoring and yield estimation, (ii) agriculture drought monitoring and forecasting with early warning facility, (iii) catchment monitoring is required for water resources, (iv) rangeland productivity monitoring, (v) monitoring water use for agriculture, (vi) tree plantation monitoring, (vii) development and management of National GIS/RS data bank, (viii) flood forecasting, early warning, and water resources monitoring system. The major challenges with regard to the availability of geospatial data in Pakistan are:

- Geospatial data are collected primarily by government agencies, and data collections are carried out as per the mandates of the respective organizations

- Geospatial data are available for sectors such as agriculture, water resources, land cover, river basins, weather, climate, and environment, but data-sharing provisions among the agencies are generally limited or non-existent

- Regular updating of the data does not happen; lack of skilled human resources is another barrier in advancing geospatial applications.

\subsubsection{Institutional Assessment}

Since SERVIR's approach depends on partner agencies to deliver the geospatial information services, an assessment of current tasks, priorities, needs, and capacities were essential to understand the overall landscape. This section gives an account of how geospatial technologies are being used by the agencies working in the $\mathrm{HKH}$ region; this is based on a specific survey conducted for this study. 


\subsubsection{Major Tasks of the Organizations}

The agencies in the HKH region perform different types of activities to deliver information services in related sectors. Among the three countries that were surveyed, it was mostly Nepal's agencies which mentioned that they carried out projects based on the need of the client. Six agencies indicated that they performed assessments using geospatial data, tools, and methods to assess development impacts on the environment and society. The agencies in Bangladesh and Nepal reported that they mainly stuck to the activities that were required to support the core/primary activities of any sector. About $34 \%$ of the agencies stated that they used geospatial technologies to address the needs of the users in a more efficient way; $28 \%$ indicated that using geospatial technologies helped them to ensure complete coverage of the problem whereby they could use multiple layers of information. Some agencies reported that they used geospatial technologies for better planning and for maintaining commitments in delivering services. The survey results revealed that the agencies prioritized activities in terms of what were most important to them (i.e., primary-focus activities) and then paid attention to secondary/other priority areas. The agencies informed that such prioritization was a tricky and complicated job since it depended on several elements like the duration and size of the project and organizational policy and donor priorities.

\subsubsection{Requirement and Use of Data}

The agencies that were interviewed mentioned about 15 thematic categories (Fig. 3.2), where they use various types of geospatial data and methods. On average, land use and land cover, land topography and elevation, and information about administrative boundaries were mentioned as the most important thematic categories that use geospatial data. The countries, however, provided different accounts in this regard. Most of the agencies in Bangladesh indicated that they needed hydro-climatic data on a daily and weekly basis because they needed to develop early warning forecast products to deal with floods of various kinds (e.g., riverine floods, flash floods, abnormal water surge in the coastal areas) and also to predict related vulnerabilities like riverbank erosion, crop loss, and landslides. The agencies in Nepal mentioned that they needed all kinds of data since the variation in elevation and topography results in significant variation in climatic variables. The agencies in Afghanistan stated that they mostly depended on annual data to produce geospatial products aimed at irrigation planning and also to assess impacts of hazards like drought, floods, and landslides.

Land use and land cover, topography, land elevation, administrative units, and infrastructure are the top five categories of data used by agencies relying on geospatial technologies in Bangladesh, Afghanistan, and Nepal. The agencies indicated during the institutional survey that these data sets helped by way of inputs to undertake different types of analysis and to produce map products, trend 


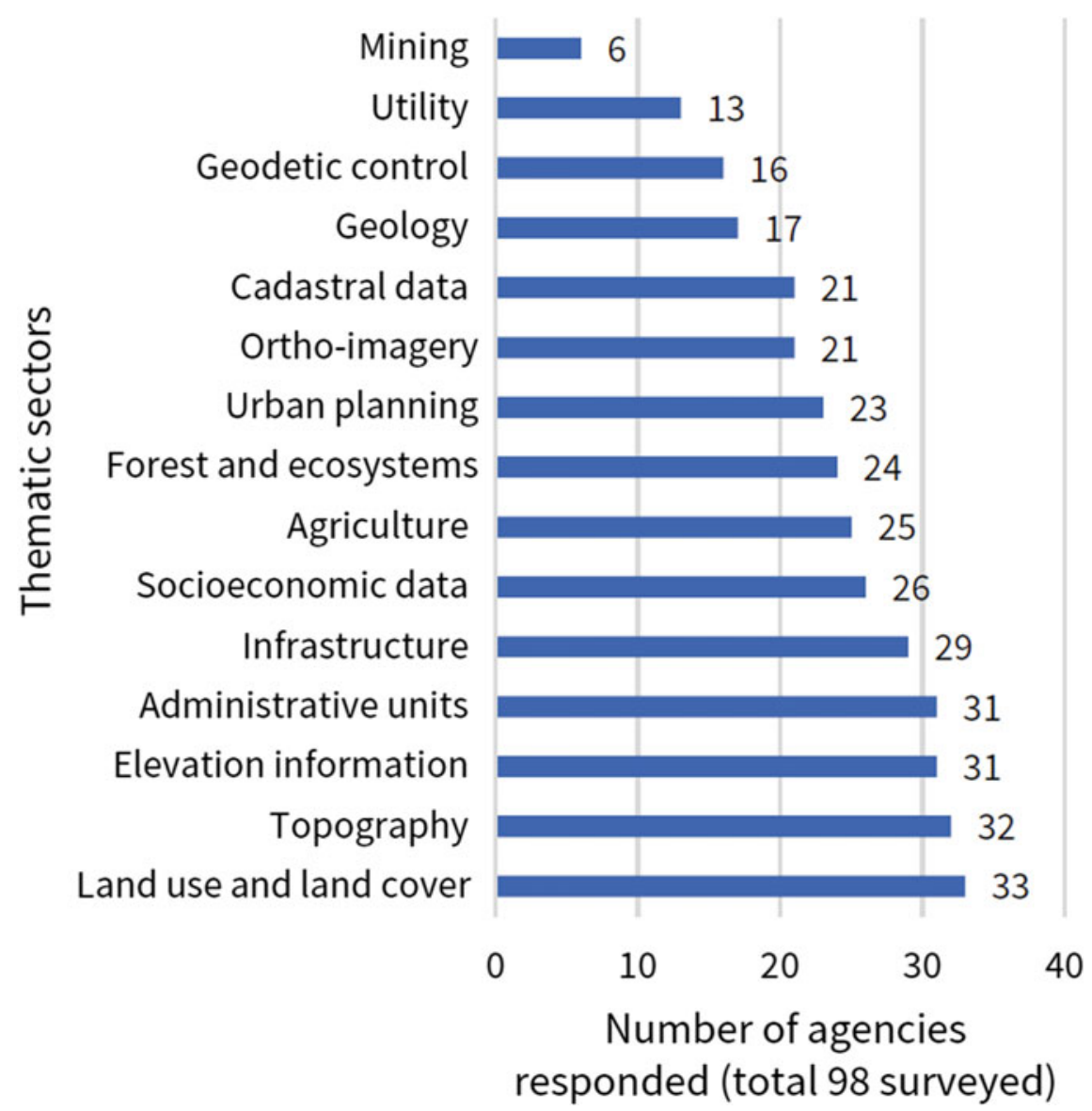

Fig. 3.2 Application areas of geospatial technologies

analyses, impact assessments, and modeling results for the monitoring and planning of resources. The survey also showed that mining and service-utility data were the least used by the agencies in these three countries.

\subsubsection{Data-Sharing Provisions}

The status of exchange and sharing of geospatial data among the agencies are limited in all the countries in the HKH region. These limited sharing provisions exist because of the absence of necessary policy, infrastructure, and resources. For example, in Pakistan, geospatial data are produced and archived by agencies like the Survey of Pakistan, SUPARCO, the Revenue Department, and the Geological Survey of Pakistan; but institutional, legal, and technical arrangements are not in 
place for coordination among these agencies (Ali 2009). In Bangladesh, the primary agencies that produce, use, and deliver geospatial data are SoB and SPARRSO, which is under the Ministry of Defense. So, for accessing their data, the users have to go through complicated and time-consuming administrative processes and security checks; indeed, items like topographical maps created by SoB still come under the category of classified products and are restricted for public use. Other agencies in Bangladesh, like the Department of Land Records and Survey (DLRS) under the Ministry of Land, the Department of Public Health and Engineering (DPHE), and LGED do use geospatial technologies in different capacities and purposes, but they also need to follow cumbersome administrative processes to share their data with other agencies. Then there's the issue of copyright such as when it comes to reproducing spatial data by digitizing hard-copy maps produced by third parties.

But a few agencies did state that their offices had designated personnel for managing geospatial data sharing with other agencies and that they shared data regularly. Interestingly, Nepal, Pakistan, Afghanistan, and Bangladesh are currently trying to put in place a National Spatial Data Infrastructure (NSDI) so that their central archives are linked to each other, and the dissemination/sharing of spatial data is enabled in an effective manner. Most of the agencies indicated that poor data quality, shortage of human resources, and hardware resources are the major challenges for data sharing.

\subsubsection{Institutional Needs and Priorities}

The study reveals that though the introduction of geospatial technologies in different application domains started in the HKH region in the 1990s, the proper integration and institutionalization of the system have not yet taken place in the public agencies. While professional activities are taking place, they are by way of time-bound projects where external partner agencies play vital roles in supplying resources and technical solutions. And the funds generally cease with the termination of a project; so, there's no continued support to enable regular operational activities and to update the data/products. In most of the cases, the allocation of resources from the revenue sources is negligible because of the non-existence of policies and strategies in this regard. This uncertainty causes diminishing use/reuse and hampers the sharing of the geoinformation with other agencies. Over time, with the help of partnerships with external agencies when the hardware and software, and EO data become less costly and more available, and the agencies become more familiar with the geospatial tools, methods, and applications, a better ground could be laid for more sustainable and robust use/integration of geospatial technologies in different areas. In this regard, the interviewees had several suggestions (Table 3.3), such as in terms of developing human resources who can better handle geospatial data, tools, and models and where appropriate strategies are in place so that the 
Table 3.3 Suggestions for improved geospatial applications

\begin{tabular}{l|l}
\hline Priority areas & $\begin{array}{l}\text { Number and percentage of agencies } \\
\text { that responded (multiple responses) }\end{array}$ \\
\hline 1. Skill development training & $32(21 \%)$ \\
\hline 2. Hardware support and upgradation & $26(17 \%)$ \\
\hline 3. Necessary fund flow & $26(17 \%)$ \\
\hline 4. Retain the trained workforce in the organization & $25(16 \%)$ \\
\hline 5. Need appropriate policy (e.g., NSDI) & $23(15 \%)$ \\
\hline $\begin{array}{l}\text { 6. Access to scale-specific and required } \\
\text { data when necessary }\end{array}$ & $20(13 \%)$ \\
\hline
\end{tabular}

Table 3.4 Country-specific priorities for improving geospatial applications

\begin{tabular}{l|l|l}
\hline Priority areas & \multicolumn{2}{l}{} \\
\hline Priorities of Nepal & Priorities of Bangladesh & Priorities of Afghanistan \\
\hline 1. Need appropriate policy & 1. Skill development training & 1. Appropriate policy \\
2. Skill development training & 2. Hardware support & 2. Skill development training \\
3. Hardware support & 3. Necessary funding & 3. Retain human resources \\
4. Necessary funding & 4. Retain human resources & 4. Access to data \\
5. Retain human resources & 5. Access to data & 5. Necessary funding \\
\hline
\end{tabular}

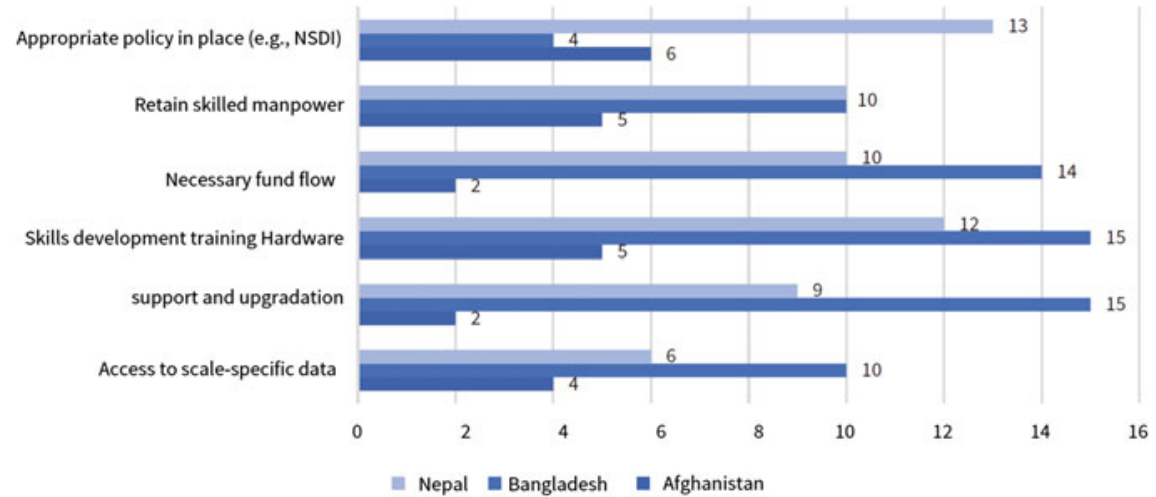

Fig. 3.3 Country-wise priorities for more effective geospatial applications (number of agencies; multiple responses counted)

agencies can retain skilled human resources. However, as Table 3.3 shows, when it comes to priorities of all the countries combined, they are slightly different from the options and priorities of the individual countries (Table 3.4; Fig. 3.3). 


\subsection{Conclusions and Major Findings}

The study on the decision-making landscape of the different countries in the HKH region has provided an in-depth understanding of the degree of applications of geospatial data and tools for various application domains. The study reveals that the introduction of geospatial technologies in different application domains in the HKH region took place in the 1990s. However, proper integration and institutionalization of the system has not yet happened in the case of the public agencies of the region. Activities are taking place only on an ad hoc basis in all the relevant sectors: agriculture and food security; water resources and hydro-climatic disaster management; land cover and land use; ecosystems; and weather and climate. And these activities are mostly time-bound projects where external partner agencies play vital roles in supplying resources and technical solutions. All these resources generally cease with the termination of the contract with the external partners and thus cannot continue providing support to perform regular operational activities and to update the products. The required allocation of resources from the revenue sources is sparse because of the non-existence of policies and budgetary provisions. This lacuna also leaves its impacts on proper use/reuse and the sharing of geoinformation with other agencies.

Agencies in the $\mathrm{HKH}$ region are using geospatial technologies within the background contexts mentioned above for improving the services they deliver for user benefits. However, it is important to note that in recent times, the cost of hardware and software has dropped, and EO agencies like NASA have made their data available for free. Against such a backdrop and when the agencies become more familiar with the geospatial tools, methods, and applications, a firmer ground could be laid for more sustainable and robust integration of geospatial technologies with the agencies that are interested in using this technology. In this regard, several recommendations (below) have come from the national agencies that were interviewed for this study; the implementation of these suggestions would go a long way in ensuring a strong foothold for geospatial data infrastructure in the $\mathrm{HKH}$ region. It is imperative to mention here that in the given contexts and as an interim solution (unless and until national agencies develop necessary policies), the promotion of online geospatial systems such as Google Earth Engine (GEE) and free software like QGIS could play vital roles because these will help the agencies to avoid the burden of data production and archiving, and also relieve them of the need to procure and maintain expensive hardware facilities. The major findings of this research and the recommendations are grouped into two categories; the first category presents the findings and recommendations relating to geospatial data and applications; while the second category reveals the institutional policy gaps.

\section{Findings on Geospatial Resources (Data, Applications)}

- Geospatial applications are needed primarily to assess disaster impacts and early warning systems in the HKH region: The study suggests that the agencies need various types of geospatial data during different time frames -such as 
daily, seasonal, annual, and decadal-for conducting impact assessments of hydro-climatic disasters (e.g., flood-affected-area mapping in Bangladesh; landslide susceptibility in Nepal-Islam and Sado 2000; Haq et al. 2012; Regmi et al. 2014) and change detection in irrigated agriculture (e.g., in the case of Afghanistan-Haack et al. 1998), as well as for providing early warning and forecasts on droughts and landslides.

- National communication reports mention about the need for data and knowledge products: The governments in their international communication reports (e.g., reports written for UNFCCC, CBD, and UNCTAD) refer to the need for geospatial data for producing high-quality reports with valuable information.

\section{Findings on Institutional Policy Gaps}

- The apex management of the agencies play important roles in making decisions: The results suggest that the apex management of an organization plays a vital role in making decisions regarding the integration of geospatial applications in the service-delivery processes. Sensitizing them is, therefore, crucial to incorporate geospatial applications into organizational mandates.

- Activity prioritization depends on the core mandates of an agency: The survey results reveal that agencies prioritize activities as per their organizational mandates wherein there are primary-focus activities and then secondary priority areas.

- Time-bound, project-based geospatial applications: The study findings suggest that in most of the instances, government agencies are approached by international agencies to incorporate geospatial technologies to improve their decision-making and service-delivery processes. These international agencies generally come with geospatial data (where necessary), technical solutions, and the human resources to provide support within a specific period for which they sign the agreement. The geospatial laboratories that are developed during the project time generally lose the necessary attention from the host agency and the apex body of a sector (like ministry) when the project ends. This is mainly because giving importance to such activities are neither indicated in the sector's policy papers nor mentioned in its organizational strategy documents. Therefore, it becomes challenging for the host agencies to sustain skilled human resources and regular updating of geospatial data. There's lack of a recurrent budget from revenue sources for upgradation of hardware and software facilities and archiving and dissemination.

- The sharing provisions of geospatial data are poor among the agencies: Data-sharing provisions are low among the agencies in the HKH region for several reasons. These are: (i) absence of policies, legal frameworks, and mandates; (ii) absence of a central coordinating authority to produce, archive, and share data, not to mention the non-existence of a geospatial data-sharing clearinghouse; (iii) absence of the metadata of the geospatial data in most cases - thus, it becomes difficult to know about the accuracy, consistency, sources, 
and scale of the data, resulting in the agencies shying away from receiving the data of other agencies - instead, they prefer to produce the same data again; (iv) limited understanding about the usefulness of sharing geospatial data; and (v), inadequate human and financial resources with the agencies to perform data-sharing activities.

\section{References}

Ali A (2009) Spatial data infrastructure for land administration in Pakistan. Paper presented in the conference titled 'Spatial data serving people: land governance and the environment - building the capacity', Hanoi, Vietnam, 19-22 Oct 2009

Ali A, Ahmad M (2013) Geospatial data sharing in Pakistan: possibilities and problems. In: Conference: global geospatial conference 2013, Addis Ababa, Ethiopia

Bastiaanssen WGM, Ali S (2003) A new crop yield forecasting model based on satellite measurements applied across the Indus Basin, Pakistan. Agric Ecosyst Environ 94(3):321-340

Chantillon M, Crompvoets J, Peristeras V (2017) The governance landscape of geospatial e-services- the Belgian case. ISPRS Int J Geo-Inf 6

Devkota KC, Regmi AD, Pourghasemi HR, Yoshida K, Pradhan B, Ryu I Chang, Dhital MR, Althuwaynee OF (2012) Landslide susceptibility mapping using certainty factor, index of entropy and logistic regression models in GIS and their comparison at Mugling-Narayanghat road section in Nepal Himalaya. Nat Hazards 65:135-165

Gaurav K, Sinha R, Panda PK (2011) The Indus flood of 2010 in Pakistan: a perspective analysis using remote sensing data. Nat Hazards 59:1815-1826

GEOBUIZ (2018) Geospatial industry outlook \& readiness index. Geospatial Media and Communications

Haack B, Wolf J, English R (1998) Remote sensing change detection of irrigated agriculture in Afghanistan. Geocarto Int 13(2):65-75

Haq M, Akhtar M, Muhammad S, Paras S, Rahmatullah J (2012) Techniques of remote sensing and GIS for flood monitoring and damage assessment: a case study of Sindh province, Pakistan. Egypt J Remote Sens Space Sci 15:135-141

ICIMOD (2016) Report of national consultation workshop on needs assessment for SERVIR-HKH in Pakistan. Workshop held on February 23 at Pakistan council of research in water resources (PCRWR), Islamabad

Islam MM, Sado K (2000) Development of flood hazard maps of Bangladesh using NOAA-AVHRR images with GIS. Hydrol Sci J 45(3):337-355

Marvasti AB (2004) Qualitative research in sociology: an introduction. SAGE Publications Ltd, London

Raadschelders JCN, Whetsell TA (2017) Conceptualising the landscape of decision making for complex problem solving. Int J Public Adm 41:1132-1144

Regmi AD, Devkota KC, Yoshida K, Pradhan B, Pourghasemi HR, Kumamoto T, Aykut A (2014) Application of frequency ratio, statistical index, and weights-of-evidence models and their comparison in landslide susceptibility mapping in Central Nepal Himalaya. Arab J Geosci 7 (2):725-742 
Open Access This chapter is licensed under the terms of the Creative Commons Attribution 4.0 International License (http://creativecommons.org/licenses/by/4.0/), which permits use, sharing, adaptation, distribution and reproduction in any medium or format, as long as you give appropriate credit to the original author(s) and the source, provide a link to the Creative Commons license and indicate if changes were made.

The images or other third party material in this chapter are included in the chapter's Creative Commons license, unless indicated otherwise in a credit line to the material. If material is not included in the chapter's Creative Commons license and your intended use is not permitted by statutory regulation or exceeds the permitted use, you will need to obtain permission directly from the copyright holder.

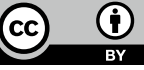

